\title{
Co-occurrence pattern of ground beetle (Coleoptera, Carabidae) assemblages along pollution gradient in scotch pine forest
}

\author{
R. Kędzior ${ }^{1,4}$, A. Kosewska ${ }^{2}$ and T. Skalski ${ }^{3}$ \\ ${ }^{1}$ Department of Ecology Climatology and Air Protection, University of Agriculture, Krakow, Poland \\ ${ }^{2}$ Department of Entomology, Phytopathology and Molecular Diagnostic, University of Warmia and Mazury in Olsztyn, \\ Prawochenskiego 17, 10-687 Olsztyn, Poland \\ ${ }^{3}$ Institute of Biology, Jan Kochanowski University of Kielce, Poland \\ ${ }^{4}$ Corresponding author.E-mail: r.kedzior@ur.krakow.pl
}

Keywords: Body size, Carabidae, Contamination, C-score, Heavy metals.

\begin{abstract}
Over the last 30 years there has been a great deal of interest in investigating patterns of species co-occurrence across space and time, which may be shaped by interspecific competition for shared resources. A good model of co-occurrence mechanisms is developed among predatory animals along a pollution gradient, where shared resources become more limited in more contaminated areas and the energy budget for detoxification is much higher. Community disassembly by heavy metal pollution may occur when the presence of toxic elements shifts patterns of species co-occurrence from structured to random. On the other hand, limited resources on a pollution gradient should lead to higher competition between dominant species. Disassembly may entail the loss of existing co-evolved interactions among species, which has ramifications for community dynamics and the quality of the functioning of polluted ecosystems. We expect an assemblage dominated by competitive species interactions to exhibit a significant segregation of taxa, whereas one dominated by mutualistic or syntrophic interactions would exhibit an aggregation of taxa. Responses of Carabidae co-occurrence patterns and changes in body size measures to heavy metal concentrations were investigated in a zinc contamination gradient in a Scots pine forest in the vicinity of Olkusz (southern Poland), at 12 study sites. The zinc concentration in the humus layer varied between $108 \mathrm{mg} \mathrm{kg}^{-1} \mathrm{dw}$ to $6150 \mathrm{mg} \mathrm{kg}^{-1} \mathrm{dw}$. We used the $\mathrm{C}$-score index, between all possible species pairs in a matrix. The ground beetle assemblages from the reference sites showed a significant segregation pattern. Community disassembly occurred only among assemblages in heavily polluted sites. The average value of skewness and kurtosis were significantly higher in the highly contaminated sites, indicating the greater proportion of small-bodied species in contaminated areas. The Gini coefficient was highest in the low contaminated sites, indicating the body-size inequality of carabid assemblages was greatest in the uncontaminated areas. Our data suggest that increased pollution contributes to the extinction of sensitive forest specialists with large body size and higher competitive abilities, leading to replacement by less sensitive generalists, with smaller body size and that the co-occurrence of species on heavily polluted sites is a result of unstable interactions between species in communities.
\end{abstract}

Nomenclature: Aleksandrowicz (2004).

Abbreviations: L-low contaminated localities; H-high contaminated localities.

\section{Introduction}

Intensive industrial activity leads to increasing pollution of the natural environment by heavy metals. This poses a threat to both plants and animals, and thus to humans as well (Gallagher et al. 2008, Żmudzki and Laskowski 2012). The concentration of heavy metals in the natural environment is influenced by many factors directly associated with the source and form of the pollutants, but also by soil parameters such as soil $\mathrm{pH}$, organic matter content, granulometric composition, soil sorption capacity, and the mobility of a given trace element in the environment (Gall et al. 2015). Most heavy metals which are harmful to the environment are most heavily concentrated in the soil, thus acting as a strong stressor for many organisms that are closely associated with the soil (Stefanowicz et al. 2008, Holmstrup et al. 2010).
Among diverse epigeic fauna, ground beetle assemblages, structurally and functionally diverse organisms with a wide range of body size and a high level of dietary specialization (herbivores-predators), play a very important role in the functioning of forest ecosystems (Koivula 2011, Skłodowski 2014, Skalski et al. 2015a). In areas contaminated with heavy metals, they are a good bioindicator of the negative impact of their concentration both at the level of the individual and in the structure of assemblages or interspecies interactions (Bednarska et al. 2009, Butovsky 2011, Skalski et al. 2015a,b). Severe contamination of the soil environment by heavy metals causes an increase in mortality, especially in organisms with soft and delicate body exoskeleton (e.g., the larvae of beetles of the species Pterostichus oblongopunctatus, ants Myrmica rubra, or spiders) (Możdżer et al. 2003, Grześ 2010, Żmudzki and Laskowski 2012). Heavy metals have also been shown to affect metabolism, physiology and life 
history traits (Fountain and Hopkin 2004), especially body size, in which changes are clearly observed along gradients of environmental disturbances (Ribera et al. 2001, Magura at al. 2006). Using computer-centred video tracking in laboratory Bayley et al. (1995) showed that in laboratory experiment the locomotor behaviour of adult Pterostichus cupreus was associated with copper-induced internal structural damage during larval development. In the field studies at the community level, negative effects of heavy metal contamination on species diversity parameters have been noted as well (Skalski et al. 2010, 2015ab, Żmudzki and Laskowski 2012), although the trend is not always the same (Skalski et al. 2011). However, little attention has been devoted to determining the impact of heavy metals on interspecific interactions.

In natural systems, the co-occurrence of species is strictly determined by numerous factors. The most important of these are the habitat conditions and habitat resources that shape the species structure of assemblages. In stable ecosystems, predator-prey interactions and interspecific competition are also very important factors determining the co-occurrence of species (Cody and Diamond 1975). Theoretical models indicate that the species composition of local assemblages depends on the niches shared by species (Chase and Leibold 2003). This theory assumes that there are species in assemblages competing for resources, so that their coexistence is much lower than would result from chance (Diamond 1975). On the other hand, an aggregation model is possible, which assumes that if resources are present in the form of small patches, we can expect higher coexistence of species than would result from chance. Each of these theories, however, assumes that the organisms present in the assemblages are in equilibrium and thus are stable in time and space. But what will happen when a disturbance takes place in the habitat and one of the species maintaining equilibrium in the assemblage is completely eliminated or its density is drastically reduced? We may expect that a new assemblage will appear, having a different structure and a different species composition than the previous one. The previous relationships resulting from competition will be eliminated, leading to the formation of a coexistence pattern similar to the randomized model (Gotelli 2000, Sanders et al. 2003, Banado et al. 2005, Sanders et al. 2007).

Forests contaminated with heavy metals, in which ecosystem functioning is severely disturbed, provide a good testing ground for determining the impact of contamination on the coexistence of ground beetles (Coleoptera, Carabidae). In addition, we used the parameter of carabid body size as an indicator of the impact of environmental disturbances on the functioning of entire ecosystems. This is possible because body size is strongly correlated with many other life history traits (e.g., dispersal power, reproduction rate and time of development) (Šerić Jelaska and Durbešić 2009). The selection of study sites located along a $\mathrm{Zn}$ contamination gradient made it possible to put forth the following hypotheses: (i) in a gradient of heavy metal contamination, the coexistence of species takes the form of a distribution significantly different from random distribution, and a phenomenon occurs whereby some species are excluded by others; (ii) in highly contaminated areas the random distribution of species occurs, which may indicate the extinction of species with high competitive potential; (iii) large species are eliminated in a Zn contamination gradient and in the absence of competition small species with greater environmental plasticity appear.

\section{Materials and methods}

\section{Study area and sampling}

The research was carried out in the vicinity of the Bolesław zinc and lead smelter located near Olkusz in southern Poland (Location N/E 50 $27^{\prime}, 1^{\circ} 47^{\prime}$ ). A gradient of four study sites was selected in the area within a radius of $31 \mathrm{~km}$ from the source of heavy metal emissions, where Barber traps were set and soil samples were taken in triplicate (Fig. 1). The environmental conditions at the sites were similar; the dominant plant communities were sub-Atlantic mesic pine forest (Leucobryo-Pinetum) with elements of Sambuco-Salicion and eutrophic beech forest (Fagion sylvaticae), with a similar age structure and tree species composition (Szafer et al. 1976, Skalski et al. 2010, 2015b). Two sites (distance between them exceeded $3 \mathrm{~km}$, and radius from smelter about $4 \mathrm{~km}$ ) were chosen in the immediate vicinity of the smelter (designated as highly contaminated sites). The average $\mathrm{Zn}$ content in the soil was $3957.2 \mathrm{mg} / \mathrm{kg}$. In addition, two sites (distance from each other more than $9 \mathrm{~km}$, and radius from emission source

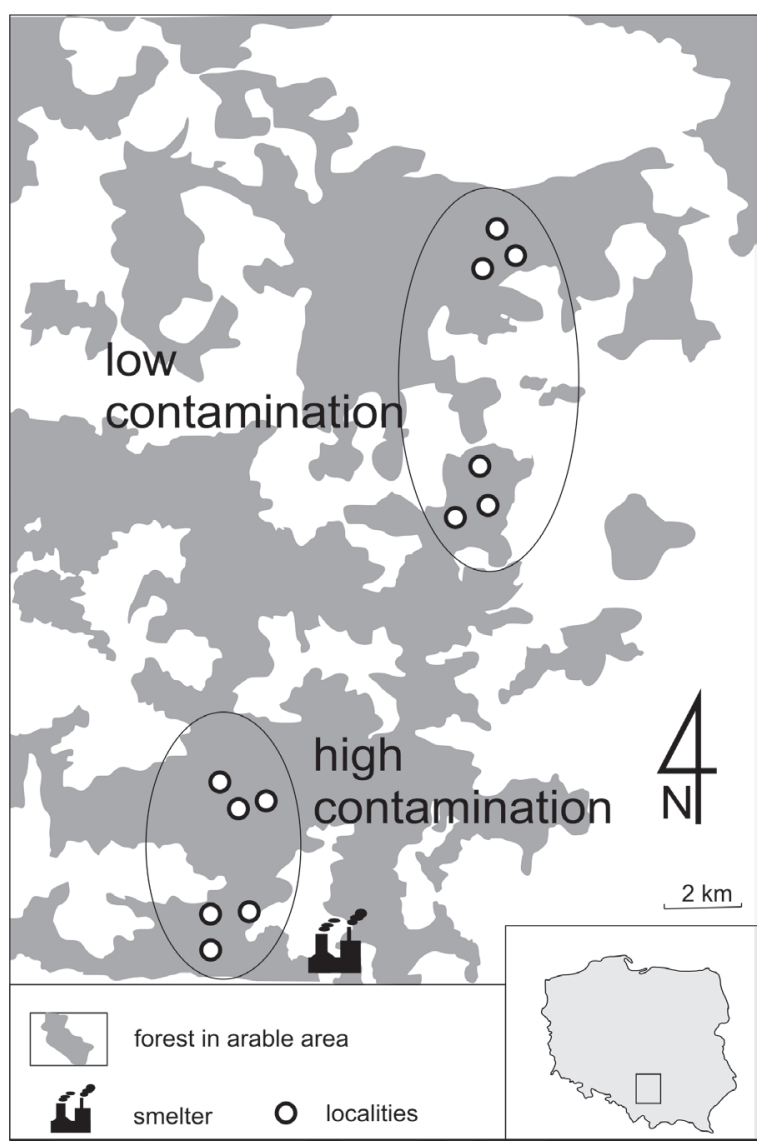

Figure 1. The map of the study area with distinction of high and low contaminated sites in the vicinity of Olkusz, southern Poland. 
more than $20 \mathrm{~km}$ ) were selected in areas where the concentration of metals was below the threshold limits for the region (designated as sites with low contamination). In these areas, the mean $\mathrm{Zn}$ content was $166.4 \mathrm{mg} / \mathrm{kg}$. We used the data from permanently monitored sites since 2001 (Stone et al. 2001, Stefanowicz et al. 2008, Skalski et al. 2010, Żmudzki and Laskowski 2012). At each site in the zinc contamination gradient, three replications of rows of 10 Barber traps were set up at random. The data of the ten traps of each row were pooled, resulting in six samples for high contaminated sites $(\mathrm{H})$ and six samples for low contaminated sites (L). The distance between replicates was higher than $500 \mathrm{~m}$. The traps were plastic cups $7 \mathrm{~cm}$ in diameter and $10 \mathrm{~cm}$ deep, placed in the ground with the rim level with the surface and filled with ethylene glycol. Samples were collected eight times in 2012, from May to early October.

\section{Data analysis}

The degree of co-occurrence of the species in the assemblages in the $\mathrm{Zn}$ contamination gradient was determined using the $\mathrm{C}$-score index $\left(\mathrm{C}_{\mathrm{ij}}\right)$ proposed by Stone and Roberts (1990), described by the following formula:

$\mathrm{C}_{\mathrm{ij}}=\left(\mathrm{r}_{\mathrm{i}}-\mathrm{S}\right)\left(\mathrm{r}_{\mathrm{j}}-\mathrm{S}\right)$;

where $r_{i}$ is the row total for species $i ; r_{j}$ is the row total for species $\mathrm{j} ; \mathrm{S}$ is number of sites that contain both species ( $\mathrm{i}$ and j) (Heino 2009). This index measures the number of cases where species A appears at site 1 and is absent from site 2, while species $\mathrm{B}$ has the reverse distribution pattern. The C-score is thus the average number of records between all pairs of species in the assemblage. When the indices are higher than the values resulting from random distribution, this is a case of species segregation, whereas indices lower than random values indicate aggregation (Gotelli 2000). Cooccurrence values for random species patterns were generated using ECOSIM software.

To test the relationships between the pollution level and carabid body size we used modified Lorenz curves, where the cumulative proportion of ranked body size of ground beetle is plotted against the cumulative proportion of cumulative percentage of individuals per species according to suggestion by Ulrich et al. (2008). Body size data for each species were taken from the literature (Hurka 1996). The skewness, kur- tosis and Gini coefficients were used to describe the shape of the body size distribution pattern in the ground beetle assemblages at the two types of sites (low and high contamination) (Magura et al. 2006). In addition, the significance of the skewness, kurtosis and Gini coefficients between the two types of sites (low and high contamination) was determined by one-way ANOVA. The analysis was carried out using Statistica (StatSoft 2012).

To determine the contribution of individual carabid species in the heavy metal contamination gradient, we calculated the similarity percentage (SIMPER, Clarke 1993). The analyses were performed using PAST software (Hammer et al. 2001). The one-way ANOVA was used to compare the distribution of abundances of species identified in the SIMPER analysis between locations with low and high contamination.

\section{Results}

During the field work conducted throughout the 2012 growing season we collected and identified a total of 13295 beetles belonging to 60 species of the Carabidae family. The co-occurrence of species in all localities showed a non-random pattern, as the mean $\mathrm{C}$-score value for random co-occurrence of species was statistically significantly lower than the value generated for the empirical pattern (Fig. 2, Table $1)$, indicating strong interspecific interactions in the pattern studied. The absence of random species distribution was also observed in the sites with low contamination (Fig. 2). The empirical C-score values are significantly higher than the mean simulated for random patterns (Table 1). This analysis indicates that in the reference areas there were strong mechanisms responsible for ordering the structure of assemblages in each of the study sites. A different pattern of species cooccurrence was obtained for the sites where the concentration

Table 1. Summarized results of co-occurrence analysis.

\begin{tabular}{lcccc}
\hline & $\begin{array}{c}\text { Observed } \\
\text { C-score }\end{array}$ & $\begin{array}{c}\text { Simulated } \\
\text { Means }\end{array}$ & Variance & p-value \\
\hline All localities & 3.765 & 3.418 & 0.007 & 0.00001 \\
$\begin{array}{l}\text { Low cantaminated } \\
\text { localities }\end{array}$ & 0.31 & 0.259 & 0.0004 & 0.024 \\
$\begin{array}{l}\text { High contaminated } \\
\text { localities }\end{array}$ & 0.971 & 0.963 & 0.002 & 0.398 \\
\hline
\end{tabular}
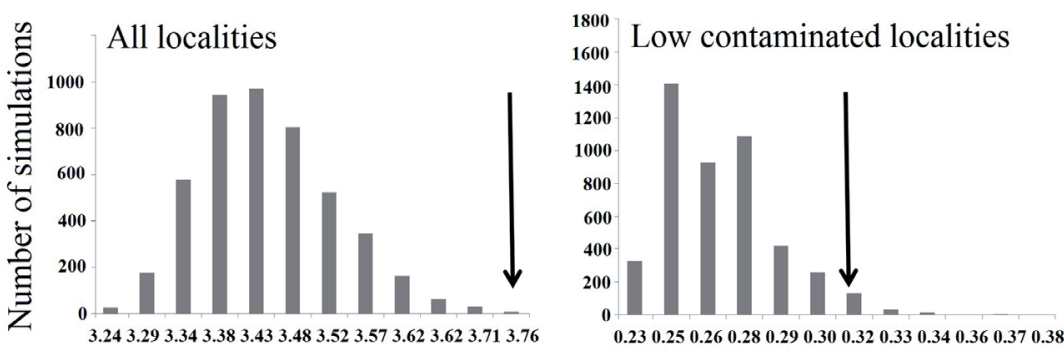

C-score values

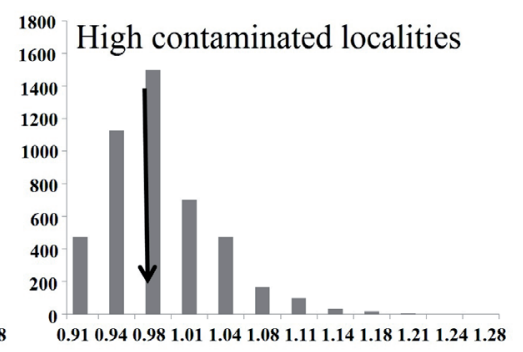

0.910 .940 .981 .011 .041 .081 .111 .141 .181 .211 .241 .28

Figure 2. Histogram of the observed and expected C-score values in the whole dataset and in sites with low and high levels of contamination. The arrows correspond to the values obtained for the recorded ground beetle distributions. 

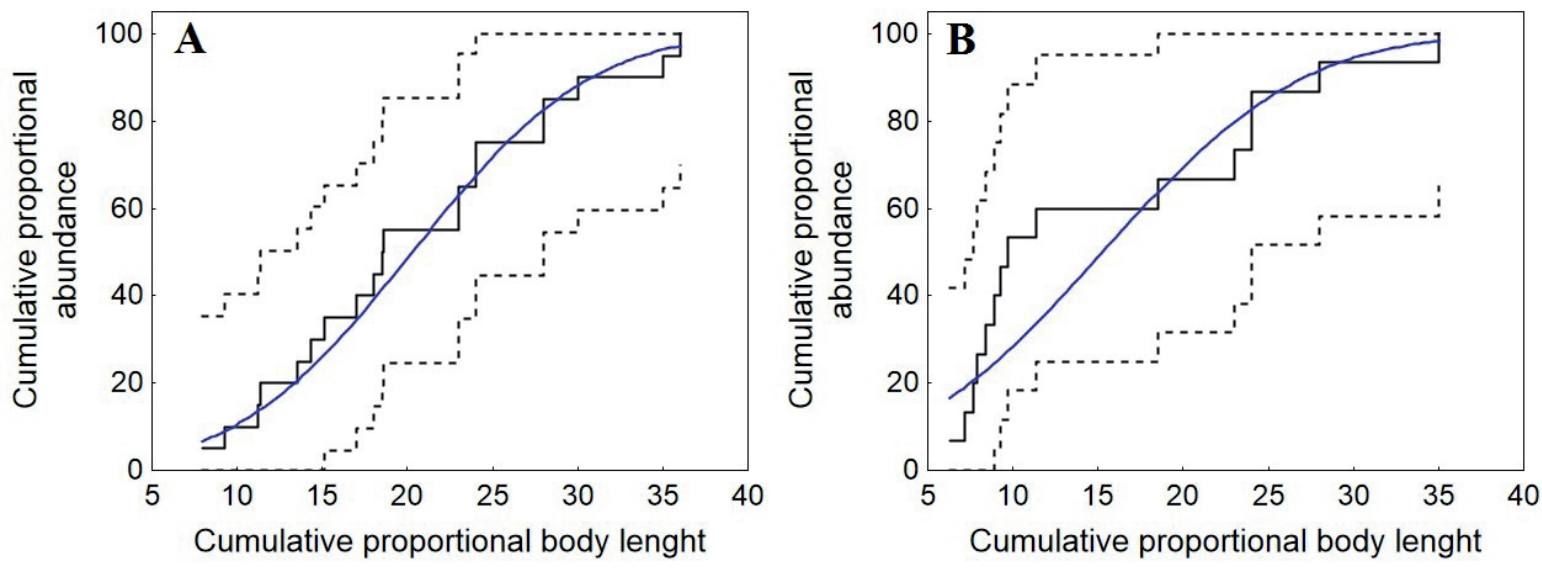

Figure 3. Modified Lorenz curves of the body size distribution of ground beetles in sites with low (A) and high (B) levels of contamination (dotted line- the intervals of probability, smooth line - the assumption of the data distribution and broken line- the strict relation between variables).
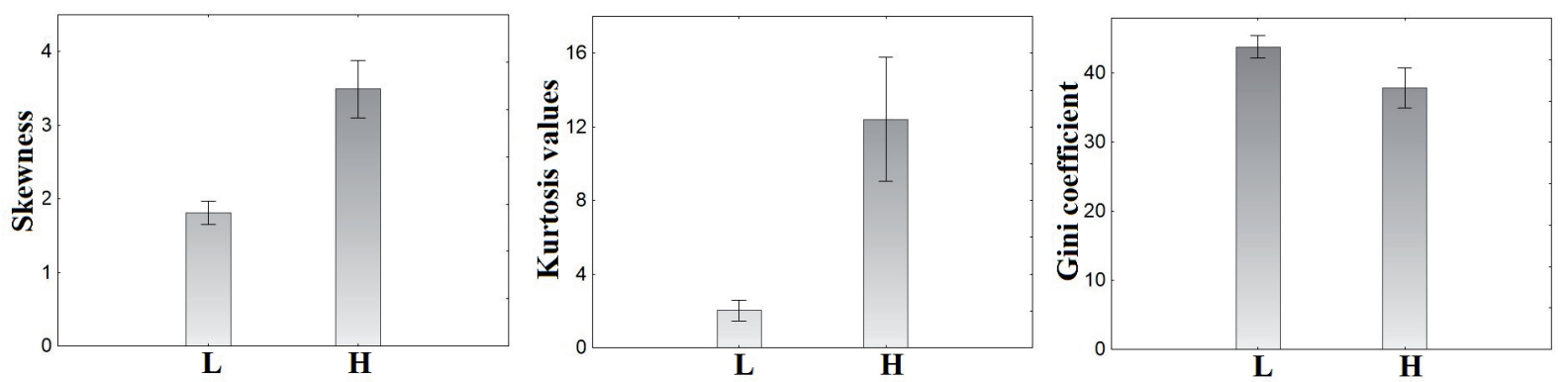

Figure 4. Mean ( \pm S.E.) skewness, kurtosis and Gini coefficients for the ground beetle assemblages in sites with low $(\mathrm{L})$ and high $(\mathrm{H})$ contamination. The whiskers indicate 0.95 confidence interval.

Table 2. The results of one-way ANOVA for the values describing the shape of the body size distribution pattern in ground beetle assemblages $\left(* \mathrm{p}<0.01, * * \mathrm{p}<0.001,{ }^{* * *} \mathrm{p}<0.0001\right)$.

\begin{tabular}{lccccc}
\hline Body size variables & SS & df & MS & F & p \\
\hline $\begin{array}{l}\text { Skewness } \\
\text { coefficient }\end{array}$ & & & & & \\
\hline $\begin{array}{l}\text { Residual } \\
\text { Contamination }\end{array}$ & 84.28 & 1 & 84.28 & 1064.61 & $* * *$ \\
$\quad$ Error & 0.79 & 1 & 8.48 & 107.14 & $* * *$ \\
\hline Kurtosis values & & & & & \\
\hline Residual & 623.85 & 1 & 623.85 & 117.89 & $* * *$ \\
$\quad$ Contamination & 323.49 & 1 & 323.49 & 61.13 & $* * *$ \\
$\quad$ Error & 52.91 & 10 & 5.29 & & \\
\hline Gini coefficient & & & & & \\
\hline Residual & 20027.93 & 1 & 20027.93 & 3917.46 & $* * *$ \\
$\quad$ Contamination & 106.92 & 1 & 106.92 & 20.91 & $* *$ \\
$\quad$ Error & 51.12 & 10 & 5.11 & & \\
\hline
\end{tabular}

of heavy metals was more than 500 times above the acceptable limit (highly contaminated sites, Fig. 2). In this case, the C-score did not differ significantly from the generated mean random occurrence (Table 1).
The modified Lorenz curves of the body size of ground beetles in sites with low and high levels of contamination had markedly different shapes (Fig. 3A and B). In the case of sites where $\mathrm{Zn}$ concentrations were low (Fig. 3A), the body size distribution in the carabid assemblages was nearly sigmoidal. In these assemblages, large and medium-sized species were present in high numbers. In contrast, in the sites that were heavily contaminated with heavy metals (Fig. 3B), the distribution of the Lorenz curve indicated a high proportion of small and medium-sized species. The effect of environmental factors on carabid assemblages can also be performed investigated on the basis of body size using the skewness, kurtosis and Gini coefficients (Fig. 4), which differ statistically significantly in the $\mathrm{Zn}$ gradient (Table 2). Both skewness and kurtosis values were statistically the highest in the highly contaminated sites $(\mathrm{H})$, indicating a greater proportion of small-bodied species in the severely contaminated environments. The Gini coefficient was highest in the sites with low contamination (L) and decreased as the degree of soil contamination increased, indicating that the body size inequality of ground beetle assemblages was greatest in the uncontaminated areas and decreased significantly in the gradient of increasing contamination (Fig. 4, Table 2).

SIMPER analysis based on the degree of dissimilarity indicates which species have the greatest influence on dif- 

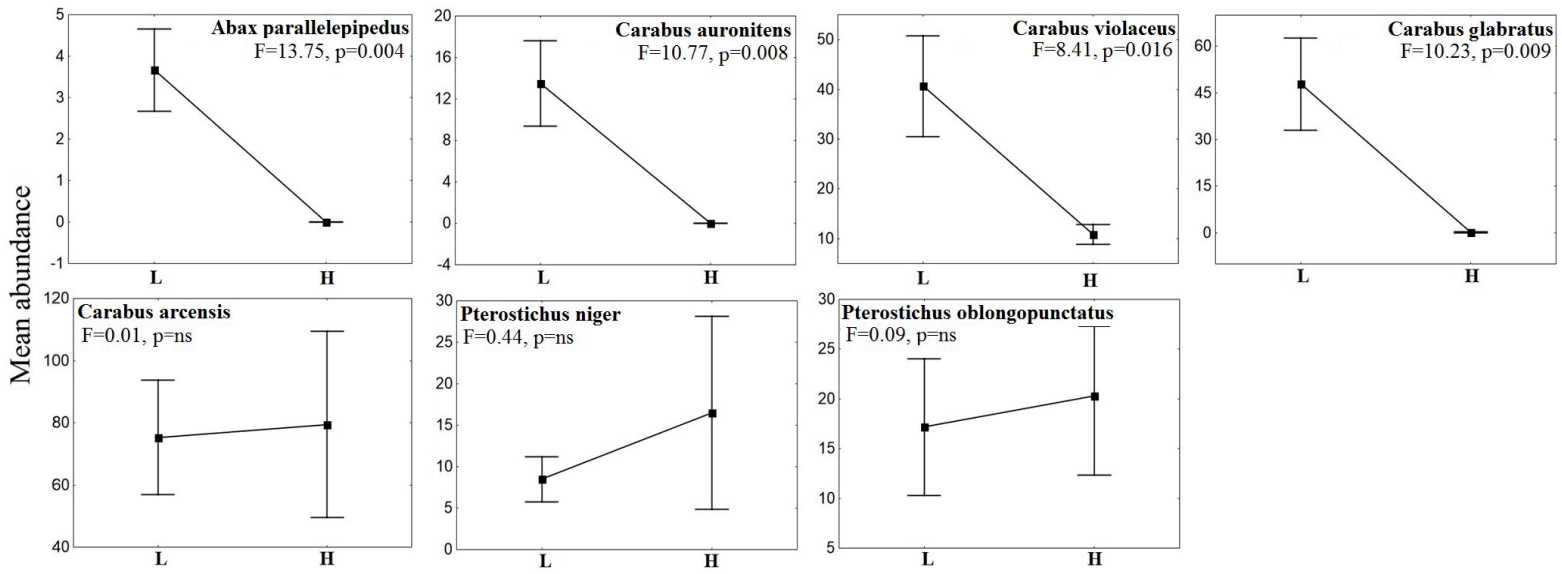

Figure 5. Mean ( \pm S.E.) abundance of ground beetle species selected in SIMPER analysis in sites with low (L) and high (H) levels of contamination, with results of one-way ANOVA. The whiskers indicate 0.95 confidence interval.

ferences between classes of assemblages. In the case of zinc contamination, the overall percentage of dissimilarity is $96.8 \%$, with just seven species responsible for $84.1 \%$. No significant difference between types of sites ( $\mathrm{L}$ and $\mathrm{H})$ was noted in the case of Pterostichus niger, P. oblongopunctatus and Carabus arcensis, despite the fact that the SIMPER analysis identified it as a species preferring contaminated sites. On the other hand, Carabus auronitens, C. glabratus, C. violaceus and Abax parallelepipedus avoided severely contaminated areas (Fig. 5).

\section{Discussion}

Effects of heavy metal contamination on the co-occurrence pattern of ground beetle assemblages

Our results suggest that the community organization of ground beetle assemblages was affected by contamination. There was clear evidence of non-randomness in the structure of communities in the reference sites (with low contamination values) as well as in all the sites considered as a whole (Fig. 2). The authors of many studies state that in undisturbed conditions, interspecific interactions in communities are determined not only by factors characterizing habitat conditions, but also by the interdependencies between species (Pitzalis et al. 2010, Blick and Burns 2011). In addition to competition, other factors that may explain the pattern of co-occurrence in assemblages include environmental parameters such as species-specific habitat associations and limited dispersal and evolutionary processes preventing species from co-occurring in the absence of species interaction (Ulrich and Gotelli 2007). In undisturbed forested areas, where environmental conditions are stable, the dominant species in carabid assemblages are mainly species with specific life history traits and generally low ecological plasticity, which as an important group of predators play a crucial role in the proper circulation of matter and energy (Thiele 1977, Gall et al. 2015). Therefore, the emergence of a stressor in the environment may significantly affect these populations in particular, but also the co-occurrence pattern of the entire assemblage (Azeria et al. 2012).
Contamination of the soil by heavy metals strongly affects living organisms, particularly soil fauna (Spurgeon and Hopkin 1996, Hedde et al. 2012), disturbing its basic biological processes and causing an increase in toxicity and thus mortality (Bednarska et al. 2009, Bednarska and Laskowski 2009). Many studies have confirmed their importance in biotransformation processes and biogeochemical cycles in the entire biosphere (Gadd 2010), for example in decomposition of organic matter, circulation of nutrients and formation and maintenance of soil structure. It is confirmed that in undisturbed pine forests soil fauna provide good starting points for bioindication of changes in soil properties and interactions between above-ground and below-ground soil communities (Minor 2011, Bonari et al. 2017). Their abundance, species distribution and community structure, as well as their sensitivity to habitat changes are valuable indicators of habitat quality used as well as in human transformed forest landscapes (Migliorini et al. 2012) or forests heavily disturbed by heavy metal contaminated sites (Migliorini et al. 2005). In general, in contaminated areas a decrease is observed in environmental capacity and the availability of resources, mainly food (Spurgeon and Hopkin 1996, Fountain and Hopkin 2004). This particularly affects predators feeding in the surface layers of soil, among which, as mentioned above, ground beetles are an important group. High levels of heavy metal contamination persisting in the environment are observed throughout food chains, from herbivores to predators (Gall et al. 2015). In addition, the co-occurrence pattern changes towards random patterns in such communities. We found this type of changes in the study sites where $\mathrm{Zn}$ concentrations in the soil were many times higher than the permissible standards (Fig. 2). We showed that soil contamination with heavy metals destroys assemblage structure and may substantially alter the species composition as well as the ecological relationships and connectivity of natural assemblages.

Analysis of the species composition of ground beetles in the heavy metal contamination gradient revealed an exchange of the dominant species in individual assemblage. The SIMPER analysis made it possible to distinguish species typical of forested areas (sites with low contamination) and areas 
with high concentrations of $\mathrm{Zn}$ in the soil (highly contaminated sites). The results indicate an exchange of species along the $\mathrm{Zn}$ contamination gradient, in which the dominant species in undisturbed conditions, making maximum use of environmental resources, such as Carabus glabratus, $C$. violaceus, $C$. auronitens and Abax parallelepipedus, are replaced by species with greater ecological plasticity (Pterostichus niger, Pt. oblongopunctatus and Carabus arcensis) (Fig. 5).

Variability in ground beetle body size in relation to the heavy metal contamination gradient

Our results also support the hypothesis that there is strong variability in ground beetle body size in relation to the heavy metal contamination gradient. Mean carabid body size changed significantly from small-bodied species in highly contaminated sites to large-bodied species in sites with low contamination (Fig. 4, Table 2). Larger body size in less disturbed areas and smaller size in highly disturbed areas has been discussed in multiple studies (Szyszko 1983, Magura et al. 2006, Šerić Jelaska and Durbešić 2009, Niemelä and Kotze 2009). In general, the literature states that stabilized environmental conditions favour species with large body size, which at the same time are characterized by poor dispersal capacity and greater energy expenditures in reproductive processes (Maryański et al. 2002, Bednarska et al. 2009). Such systems contain assemblages of many species whose coexistence pattern (as explained above) is ordered. Large-bodied species are an important ecological group of predators, which maintain their dominance in the environment through strong competitive effects (Brandl and Topp 1985). This situation, however, changes dramatically in areas subjected to strong pressure. In the case of our research, this negative pressure was caused by high concentrations of heavy metals in the soil. High contamination persisting in the soil environment negatively affects the diversity of soil fauna, which directly and strongly reduces food resources for a large group of predatory Carabidae specialists, e.g., of the genus Carabus (Skalski et al. 2015a). In addition, these species must expend more energy on detoxification processes, and due to their long development cycles, they suffer increased larval mortality (Bednarska and Laskowski 2009). As a consequence, we observe the extinction of large species of Carabidae and the emergence in the environment of species of smaller size such as Pterostichus niger and Pt. oblongopunctatus, having broader dietary requirements and shorter development cycles, resulting in a reduction in larval mortality (Sota 1987). Consequently, homogeneous assemblages are formed with strong dominant species with wide ecological ranges, whose distribution is random (Fig. 2).

\section{Conclusions}

We conclude that there is a strong pattern of species segregation in space between sites in the entire pollution gradient, suggesting directional replacement of species.

Ground beetle assemblages from the sites with a low level of contamination showed a significant segregation pattern, whereas in the case of sites with a high degree of contamination, the assemblages showed a random pattern, as an effect of extinction and recolonization processes.

Dominants from the reference sites, such as Carabus violaceus, C. glabratus and C. auronitens, were replaced by the smaller-bodied Carabus arcensis, Pterostichus oblongopunctatus and Pt. niger as the concentration of heavy metals increased.

Our data suggest that increased pollution contributes to the extinction of sensitive, large-bodied forest specialists with higher competitive abilities and their replacement by less sensitive smaller generalists, and that the co-occurrence of species on heavily polluted sites is a result of unstable relationships between species in communities.

Our results demonstrate that the co-occurrence pattern of ground beetles can be a useful indicator of chronic pollution in forested areas.

Acknowledgments: This study was supported by DS-3337/ KEKiOP.

\section{References}

Aleksandrowicz, O.R. 2004. Biegaczowate (Carabidae). In: Bogdanowicz, W., E. Chudzińska, I. Pilipiuk, and E. Skibińska (eds.), Fauna Polski - charakterystyka $i$ wykaz gatunków. Muzeum i Instytut Zoologii PAN. Warszawa. I: 28-42 [In Polish].

Azeria, E.T., J. Ibarzabal and C. Hébert. 2012. Effects of habitat characteristics and interspecific interactions on co-occurence patterns of saproxylic beetles breeding in tree boles after forest fire: null model analyses. Oecologia 168:1123-1135.

Banado, E.I., H.A. Regidor, H.A. Nủnez, R. Acosta and E. Gianoli. 2005. Species richness and structure of ants communities in a dynamic archipelago: effects of island area and age. J. Biogeogr. 32:221-227.

Bayley, M., E. Baatrup, U. Heimbach and P. Bjerregaard. 1995 Elevated Cooper Levels during larval development cause altered locomotor behavior in the adult carabid beetle Pterostichus $\mathrm{cu}$ preus L. (Coleoptera: Carabidae). Ecotoxicol. Environ.Safety 32:166-170.

Bednarska, A.J., I. Portka, P.E. Kramarz and R. Laskowski. 2009. Combined effect of environmental pollutants (nickel, chlorpyrifos) and temperature on the ground beetle, Pterostichus oblongopunctatus (Coleoptera: Carabidae). Environ. Toxicol. Chem. 28:864-872.

Bednarska, A.J. and R. Laskowski. 2009. Environmental conditions enhance toxicant effects in larvae of the ground beetle Pterostichus oblongopunctatus (Coleoptera: Carabidae). Environ. Pollution 157:1597-1602.

Blick, R.A.J. and K.C. Burns. 2011. Liana co-occurrence patterns in a temperate rainforest. J. Veg. Sci. 22:868-877.

Bonari, G., M. Migliorini, M. Landi, G. Protano, P.P. Fanciulli and C. Angiolini. 2017. Concordance between plant species, oribatid mites and soil in Mediterranean stone pine forest. ArthropodPlant Interaction 11:61-69.

Brandl R. and W. Topp. 1985. Size structure of Pterostichus spp. (Carabidae): aspects of competition. Oikos 44:234-238. 
Butovsky, R.O. 2011. Heavy metals in carabids (Coleoptera, Carabidae). In: Kotze DJ, Assmann T, Noordijk J, Turin H, Vermeulen R (eds.), Carabid beetles as bioindicators: biogeographical, ecological and environmental studies. ZooKeys 100:215-222.

Chase, J.M. and M.A. Leibold. 2003. Ecological Niches. Linking Classical and Contemporary Approaches. University of Chicago Press, Chicago, IL.

Clarke, K.R. 1993. Non-parametric multivariate analysis of changes in community structure. Aust. J. Ecol. 18:117-143.

Cody, M. L. and J. M. Diamond (eds). 1975. Ecology and Evolution of Communities. Harvard University Press, Cambridge., New York.

Diamond, J. M. 1975. Assembly of species communities. In: M. L. Cody and J. M. Diamond (eds), Ecology and Evolution of Communities. Harvard University Press, Cambridge, MA, USA, pp. 342-444.

Fountain, M.T. and S.P. Hopkins. 2004. A comparative study of the effects of metal contamination in Collembola in the field and in the laboratory. Ecotoxicology 13:573-587

Gadd, G. M. 2010. Metals, minerals and microbes: geomicrobiology and bioremediation. Microbiology 156:609-643.

Gall J.E., R.S. Boyd and N. Rajakaruna. 2015. Transfer of heavy metals through terrestrial food webs: a review. Environ. Monit. Assess. 187:201-222.

Gallagher, F., I. Pechmann, J.E. Bogden, J. Grabosky and P. Weis. 2008. Soil metal concentartions and productivity of Betula populifolia (gray birch) as measured by field spectometry and incremental annula growth in an abandoned urban Brownfield in New Jersey. Environ. Pollut. 156:699-706.

Gotelli, N.J. 2000. Null model analysis of species co-occurence patterns. Ecology 81:2606-2621.

Grześ, I.M. 2010. Zinc tolerance in the ant species Myrmica rubra originating from a metal pollution gradient. Eur. J. Soil Biol. $46: 87-90$.

Hammer, Ø., D.A.T. Harper and P.D. Ryan. 2001. Past: Paleontological Statistics Software Package for Education and Data Analysis. Palaeontologia Electronica 4:9.

Hedde, M., F. van Oort and I. Lamy. 2012. Functional traits of soil invertebrates as indicators for exposure to soil disturbance. Environ. Pollut. 164:59-65.

Heino, J. 2009. Species co-occurence, nestedness and guild- environment relationships in stream macroinvertebrates. Freshw.Biol. 54:1947-1959.

Holmstrup, M., A.M. Bindesbøl, G.J. Oostingh, A. Duschl, V. Scheil, H.R. Köhler, S. Loureiro, A.M. Soares, A.L. Ferreira, C. Kienle, A. Gerhardt, R. Laskowski, P. Kramarz, M. Bayley, C. Svendsen and D.J. Spurgeon. 2010. Interactions between effects of environmental chemicals and natural stressors: a review. Sci. Total Environ. 408(18):3746-62.

Hurka, K. 1996. Carabidae of the Czech and Slowak Republics. Kabourek, Zlin.

Koivula, M. 2011. Useful model organisms, indicators, or both? Ground beetles (Coleoptera, Carabidae) reflecting environmental conditions. ZooKeys 100:287-317.

Magura, T., B. Tóthmérész and G. Lövei. 2006. Body size inequality of carabids along an urbanisation gradient. Basic Appl. Ecol. $7: 472-482$.

Maryański, M., P. Kramarz, R. Laskowski and M. Niklińska. 2002. Decreased energetic reserves, morphological changes and accumulation of metals in Carabid Beetles (Poecilus cupreus L.) ex- posed to Zinc- or Cadmium- contaminated Food. Ecotoxicology 11:127-139.

Migliorini, M., A. Petroli and F. Bernini. 2002. Comparative analysis of two edaphic zoocoenoses (Oribatid mites and Carabid Beetles) in five habitats of the 'Pietraporciana' and 'Lucciolabella' Nature Reserves (Orcia Valley, cenral Italy). Acta Oecol. 23:361-374.

Migliorini, M., G. Pigino, T. Caruso, P.P. Fanciulli, C. Leonzio and F. Bernini. 2005. Soil communities (Acari Oribatida; Hexapoda Collembola) in a clay pigeon shooting range. Pedobiologia 49:1-13.

Minor, M.A. 2011. Spatianl patterns and local diversity in soil oribatid mites (Acari: Oribatida) in three pine plantation forest. Eur. J. Soil Biol. 47:122-128.

Możdżer, J.T., P. Kramarz, A. Piśkiewicz and M. Niklińska. 2003. Effects of cadmium and zinc on larval growth and survival in the ground beetle, Pterostichus oblongopunctatus. Environ. Int. 28:737-742.

Niemelä, J. and D.J. Kotze. 2009. Carabid beetle assemblages along urban to rural gradients: A review. Landsc. Urban Plan. 92:6571.

Pitzalis, M., L. Luiselli and M.A. Bologna. 2010. Co-occurence analyses show that non-random community structure is disrupted by fire in two groups of soil arthropods (Isopoda Oniscidea and Collembola). Acta Oceol. 36:100-106.

Ribera, I., S. Doledec, I.S. Downie and G.N. Foster. 2001. Effect of land disturbance and stress on species traits of ground beetles assemblages. Ecology 82:1112-1129.

Sanders, N.J., N.J. Gotelli, N.E. Heller and D.M. Gordon. 2003. Community disassembly by an invasive species. Proc. Nat. Acad. Sci. USA 100:2474-2477.

Sanders, N.J., N.J., Gotelli, S.E. Wittman, J.S. Ratchford, A.M. Ellison and E.S. Jules. 2007. Assembly rules for ant communities across spatial scales and habitats. J. Biogeogr. 34:1632-1641.

Šerić Jelaska L. and P. Durbešić. 2009. Comparison of the body size and wing form of carabid species (Coleoptera: Carabidae) between isolated and continuous forest habitats. Ann. soc. entomol. Fr. (n.s.). 45 (3):327-338.

Skalski, T., D. Stone, P. Kramarz and R. Laskowski. 2010. Ground beetle community responses to heavy metal contamination. Baltic J. Coleopterol. 10(1):1 - 12.

Skalski, T., K. Gargasz and R. Laskowski. 2011. Does of mixed diffuse pollution degrease ground beetle diversity? Baltic J. Coleopterol. 11(1):1-15.

Skalski, T., R. Kędzior, D. Kolbe and S. Knutelski. 2015a. Ground beetles as indicators of heavy metal pollution in forests. Sylwan 159:905-911.

Skalski, T., R. Kędzior, D. Kolbe and S. Knutelski. 2015b. Different responses of epigeic beetles to heavy metal contamination depending on functional traits at the family level. Baltic $J$. Coleopterol. 15(2):81-90

Skłodowski, J. 2014. Consequence of the transformation of a primeval forest into a managed forest for carabid beetles (Coleoptera: Carabidae) - a case study from Białowieża (Poland). Eur. J. Entomolo. 111(5):639-648.

Sota, T. 1987. Mortality pattern and age structure in two carabid populations with different seasonal life cycles. Res. Popul. Ecol. 29:237-254.

Spurgeon, D.J. and S.P. Hopkin. 1996. Effects of metal-contaminated soils on the growth, sexual development and early cocoon production of the earthworm Eisenia fetida with particular reference to zinc. Ecotoxicol. Environ. Safety 35:86-95. 
StatSoft. 2012. STATISTICA (data analysis software system), version 12.0. www.statsoft.com.

Stefanowicz, A.M., M. Niklińska and R. Laskowski. 2008. Metals affect soil bacterial and fungal functional diversity differently. Environ. Toxicol. Chem. 27:591-598.

Stone, L. and A. Roberts. 1990. The checkerboard score and species distributions. Oecologia 85:74-79.

Stone, D., P. Jepson, P. Kramarz and R. Laskowski. 2001. Time to death response in carabid beetles exposed to multiple stressors along a gradient of heavy metal pollution. Environ. Pollut. 113:239-244.

Szafer, W. and K. Zarzycki. 1972. Szata roślinna Polski. Tom II, PWN, Warszawa.

Szyszko, J. 1983. Methods of macrofauna investigations. In: Szujecki A, Szyszko J, Mazur S, Perliński S (eds). The Process of Forest Soil Macrofauna Formation after Afforestation of Farmland. Warsaw Agricultural University Press, Warsaw. pp. 10-16.
Thiele, H.U. 1977. Carabid Beetles in their Environments: A Study on Habitat Selection by Adaptations in Physiology and Behavior. Springer, Stuttgart.

Ulrich, W. and H.J. Gotelli. 2007. Null model analysis of species nestedness patterns. Ecology 88:1824-1831.

Ulrich, W., K. Komosiński and M. Zalewski. 2008. Body size and biomass distributions of carrion visiting beetles: do cities host smaller species? Ecol. Res. 23:241-248.

Żmudzki, S. and R. Laskowski. 2012. Biodiversity and structure of spider communities along a metal pollution gradient. Ecotoxicology 21:1523-1532.

Received November 24, 2017

Revised April 18, 2018

Accepted April 24, 2018 